\title{
IV. AUSBLICK
}

Die philosophiegeschichtlich bedeutsame Leistung der sprachanalytischen Philosophie besteht in ihrem Aufklärungspotential. Sie konnte zeigen, daß sich hinter anscheinend Selbstverständlichem ein Problem verbirgt. Ein solches Hinterfragen des scheinbar Selbstverständlichen kann als allgemeiner Grundzug aller philosophischen Reflexionen angesehen werden. Im Falle der analytischen Kritik richtete es sich allerdings gegen die Philosophie selbst bzw. gegen manche der unbedacht gebrauchten Begrifflichkeiten. Sprachkritik ist so gesehen eine notwendige Voraussetzung. Nur mit ihrer Hilfe können wir uns vergewissern, ob unsere Versuche, die Welt zu verstehen, nicht schon von vornherein zum scheitern verurteilt sind.

Der konstruktive Teil der Analysen besteht im Versuch einer Rekonstruktion der Termini und Argumente mit präzisen begrifflichen Mitteln und exakten Begründungsverfahren. Dabei bemüht man sich um eine gewisse Bescheidenheit. Kleine Probleme sollen exakt abgehandelt werden, da nur so präzise Aussagen gemacht werden können. Präzise Aussagen haben den Vorteil, einerseits informationsreicher zu sein und andererseits Widerlegungen in höherem Maß ausgesetzt zu sein als vage allgemeine Behauptungen. Daher besteht schon wissenschaftliche Genugtuung, wenn man zeigen kann, wie ein Problem nicht zu lösen ist (vgl. Kutschera 1984, S. 53).

In dieser Beschränkung auf die kritische Funktion der Sprachanalyse ist nicht mehr von der Aufhebung der Philosophie insgesamt die Rede. Das Aufdecken falscher Problem- und Fragestellungen beantwortet noch nicht, wie solche Probleme des Erkennens richtig zu stellen sind. Wollte man auf dem Standpunkt beharren, daß sich solche Fragen eben dann nicht mehr stellen lassen, verkennt man den Sachgehalt der anstehenden Frage. Es müßte nicht nur gezeigt werden, daß die Frage falsch gestellt ist, sondern darüber hinaus, daß es sich dabei um keine relevante Problemstellung handelt. Es darf bezweifelt werden, daß die zweite Behauptung aus der ersten unmmittelbar folgt. In ihrer sprachkritischen Funktion stellt die sprachanalytische Philosophie eine notwendige Voraussetzung aller philosophischen Bemühungen dar. Sie bietet die Grundlage, die Probleme genauer zu stellen, sprachanalytisches Philosophieren löst aber in der Regel keine philosophischen Probleme (vgl. Schnädelbach 1991, S. 75). 